\title{
CURRENT NOISE IN THICK AND THIN FILM RESISTORS
}

\author{
S. DEMOLDER, A. VAN CALSTER and M. VANDENDRIESSCHE \\ Laboratory of Electronics, Ghent State University, Sint Pietersnieuwstraat 41, B-9000 Gent, Belgium
}

(Received in final form September 26, 1981)

In this paper a sensitive measuring circuit is described for the measurement of current noise on high quality thin and thick film resistors. Measured data on resistors are presented and analysed.

\section{INTRODUCTION}

Thin and thick film resistors show a very low current noise level $(10 \mathrm{nV} / \mathrm{V}$ per decade), which makes current noise hard to measure. Since the industrial equipment used normally was unsatisfactory, we developed a more sensitive circuit. This circuit allows measurement of the current noise in the frequency range $0.1 \mathrm{~Hz}$ to $10^{4} \mathrm{~Hz}$ for resistors of $1 \Omega$ to $1 \mathrm{M} \Omega$ to be made. For frequencies above $1 \mathrm{~Hz}$ a single amplifier technique was used, but for the very low frequencies a cross correlation technique was applied.

From the measurements on thick and thin film resistors, it was found that $1 / \mathrm{f}$ noise is only significant for frequencies below $100 \mathrm{~Hz}$. This means that, besides the sensitivity problems of the industrial equipment, the used frequency range from $618 \mathrm{~Hz}$ to $1618 \mathrm{~Hz}$ is not always adapted to $1 / \mathrm{f}$ noise investigations, and thus the noise indexes derived from these measurements become somewhat doubtful.

On the other hand, the fact that we are able to characterize current noise, makes it possible to investigate the influence of a number of parameters. As an important parameter the influence of the geometry on the current noise was examined. The experimental results will be compared with a "grain-model" for $1 / \mathrm{f}$ noise.

\section{MEASURING CIRCUITS}

The hardest problem to solve, in thin and thick film noise measurements, is the amplification of the noise and shielding and grounding of the resistor under test. The experimental arrangement of the equipment is shown in figure 1 . Twisted cables and $\mu$-metal shields are used for magnetic field noise reduction. A careful grounding avoided ground loop as much as possible. In the case of extremely low noise resistors a bridge circuit of the resistors $\mathrm{R}$ under test is used. This avoids battery and prevents DC current to flow in the impedance transformer.

The measured noise is the average noise of the four resistors $\mathrm{R}$, provided special care is taken with the contacts (large contact areas and soldered contacts). As an example the current noise of four $100 \Omega$ wire-wounded resistors is measured. From figure 2(a), it is seen that the measured noise equals the thermal noise, and no current noise is detected as is normally expected for wire-wound resistors. But if no care is taken with the contacts, it is seen from figure 2 (b) that $1 / \mathrm{f}$ noise is detected.

The resistor noise is amplified by a low noise differential J-FET amplifier of Princeton Applied Research Corporation (PAR) origin. The transformer matches the resistor $\mathbf{R}$ to 


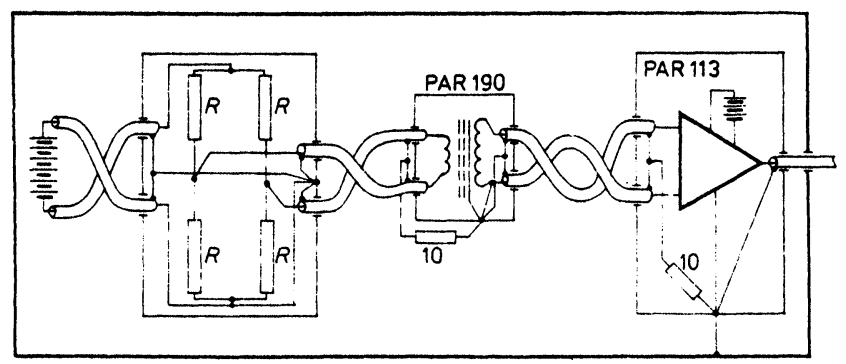

FIGURE 1 The $1 / \mathrm{f}$ measuring circuit.

the optimum source resistor of the amplifier. For $R>10 \mathrm{~K} \Omega$, the transformer may be omitted. The amplified noise is fed to a computer for the calculation of the noise spectrum by means of the Fast Fourier Transform.

In the case of extremely low frequencies, all amplifiers produce too much noise, even with matched source resistors, and thus no low level $1 / \mathrm{f}$ noise can be detected. In this case two PAR amplifiers are used, with the inputs connected in parallel. The outputs of the amplifiers are digitally crosscorrelated, which eliminates the added amplifier noise. In figure 3 the results are shown for the measurement of the thermal noise of a $20 \mathrm{~K} \Omega$ resistor. Thus it may be concluded that only with the cross correlation technique, can sensitive low frequency measurements be carred out. More details about the measuring circuits can be found in reference ${ }^{1}$.

\section{EXPERIMENTS}

To explain the resistor noise we assume that the film consists of chains of resistors $r_{v}^{2}$, as is shown in figure 4. $r_{v}$ stands for the resistance of a single bulk grain. On the other

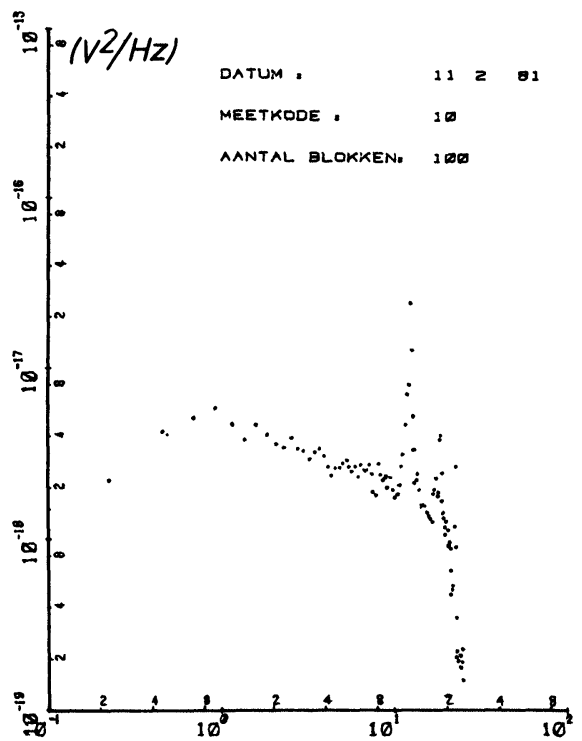

(a)

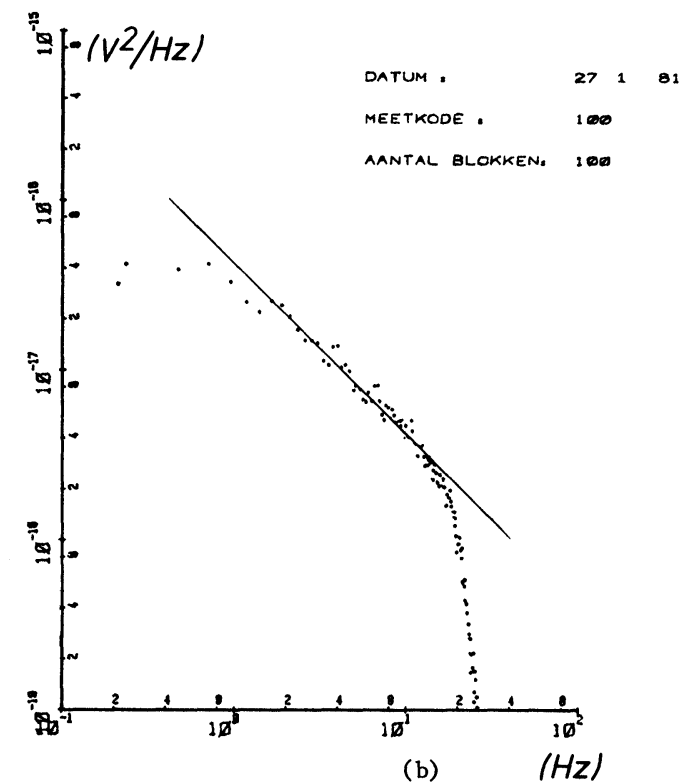

(b)

$(\mathrm{Hz})$

FIGURE 2 The noise of a bridge of wire-wounded resistors. 


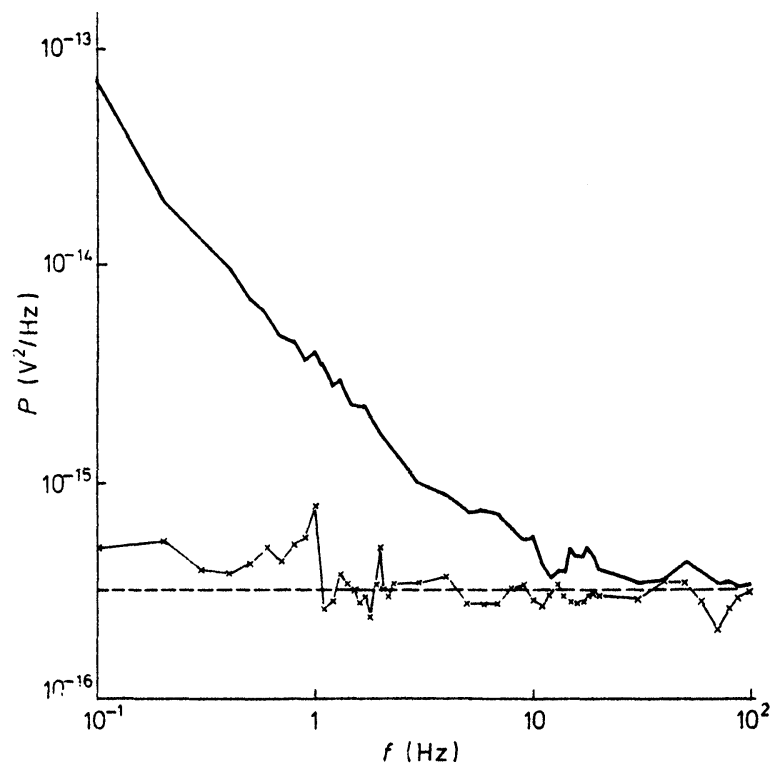

FIGURE 3 -: measured noise with single amplifier; $-\mathrm{x}$ : measured with correlation technique; ---: calculated thermal noise.

hand one may expect that the grains at the surface of the film behave different from those situated in the bulk of the film. We therefore represent a surface grain by a resistance $r_{0}$. The resistance fluctuations of the film is given by the expression:

$<\frac{\Delta R^{2}}{R^{2}}>=\frac{1}{k_{1} k_{b} k_{d}}\left(\frac{R_{o}}{R_{o}+R_{v}}\right)^{2}<\frac{\Delta r_{v}^{2}}{r_{v}^{2}}>+\frac{1}{k_{o} k_{1}}\left(\frac{R_{v}}{R_{0}+R_{v}}\right)^{2}<\frac{\Delta r_{o}^{2}}{r_{o}^{2}}$

where $k_{1}, k_{b}, k_{d}, k_{o}$ the number of grains along the directions marked on figure $4, R_{o}$ is the resistance of the surface layer, and $R_{v}$ the resistance of the bulk. From expression (1) it follows that the ratio $S$ of the surface noise to bulk noise is given by:

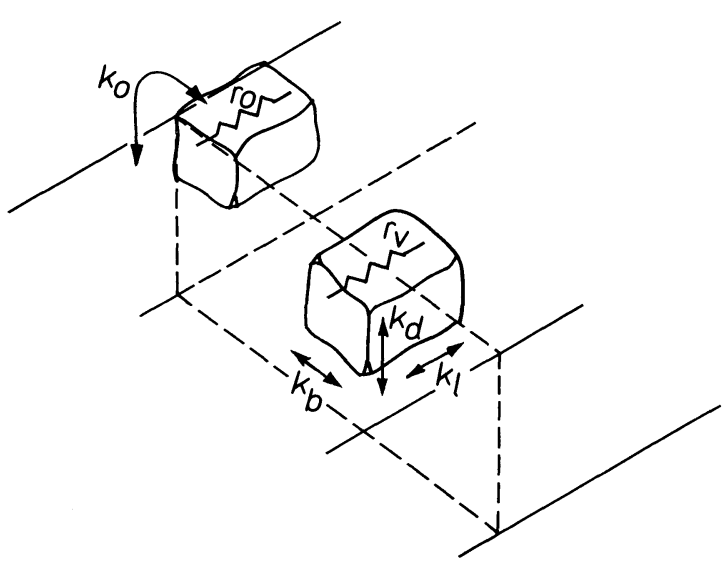

FIGURE 4 A model of a thin and thick film resistor. 
$\mathrm{S}=\frac{<\frac{\Delta \mathrm{r}_{\mathrm{o}}^{2}}{\mathrm{r}_{\mathrm{o}}^{2}}>\mathrm{k}_{\mathrm{o}} \mathrm{r}_{\mathrm{v}}^{2}}{<\frac{\Delta \mathrm{r}_{\mathrm{v}}^{2}}{\mathrm{r}_{\mathrm{v}}^{2}}>\mathrm{k}_{\mathrm{d}} \mathrm{k}_{\mathrm{b}} \mathrm{r}_{\mathrm{o}}^{2}}, \quad\left[\mathrm{k}_{\mathrm{o}} \simeq 2\left(\mathrm{k}_{\mathrm{b}}+\mathrm{k}_{\mathrm{d}}\right)\right]$.

If one assumes that surface grains are noisier than the bulk grains, but have a lower conductivity than the bulk grains, one normally obtains $\mathrm{S}$ smaller than 1 according to expression (1) because $r_{v}^{2} / r_{v}^{2} \ll 1$ and $k_{d}>1$.

Physically this means that although the surface grains may be noisier in thick films, most of the current flow through the bulk grains which makes bulk noise to become dominating. In this case expression (1) reduces to the known expression (2):

$<\frac{\Delta \mathrm{R}^{2}}{\mathrm{R}^{2}}>=\frac{1}{\mathrm{k}_{\mathrm{l}} \mathrm{k}_{\mathrm{b}} \mathrm{k}_{\mathrm{d}}}<\frac{\Delta \mathrm{r}_{\mathrm{v}}^{2}}{\mathrm{r}_{\mathrm{v}}^{2}}>$

The spectrum of the resistance fluctuations $\left\langle\Delta \mathrm{r}_{\mathrm{v}}^{2} / \mathrm{r}_{\mathrm{v}}^{2}\right\rangle$ can be put equal to $\alpha \Delta \mathrm{f} / \mathrm{f}$. Although the conduction and noise mechanisms of films composed by conductive particles embedded in a glassy matrix are still under investigation, some models state ${ }^{3}$ that conduction is determined by a tunneling through the glassy layers. The above mentioned grains and resistance $r_{v}$ may be considered to be made by the conductive particle and the insulating (glassy) layer. The modulcation of the tunnel barrier by trapped carriers may perhaps explain the $1 / \mathrm{f}$ noise of the grain.

In figure 5 the $1 / \mathrm{f}$ noise of a $10 \Omega$ resistor is shown. It is seen that $1 / \mathrm{f}$ noise only becomes significant for $\mathrm{f}<100 \mathrm{~Hz}$, which means that a measurement in the standarized frequency range $618 \mathrm{~Hz}-1618 \mathrm{~Hz}$ yields no information. To handle the measured data, we normalized as follows:

$<\frac{\Delta \mathrm{v}^{2}}{\mathrm{~V}_{\mathrm{DC}}^{2}}>=<\frac{\Delta \mathrm{R}^{2}}{\mathrm{R}^{2}}>=\mathrm{C} \frac{\Delta \mathrm{f}}{\mathrm{f}}$

where $\mathrm{V}_{\mathrm{DC}}$ the applied $\mathrm{DC}$ voltage, and $\mathrm{C}$ a dimensionless constant which characterizes the noise level. In table $I$ the measured data on low value resistors are presented. Also included is the calculated quantity $\mathrm{C} \times \mathrm{O} / \mathrm{R}$, where $\mathrm{O}$ is the area of the resistor and $\mathrm{R}$ the sheet resistance.

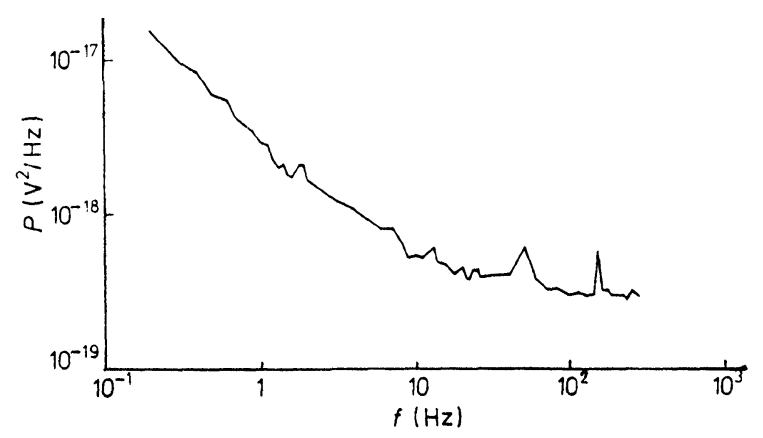

FIGURE 5 The $1 / \mathrm{f}$ noise spectrum of a $10 \Omega$ thin film resistor. 
TABLE I

The measured data

\begin{tabular}{lccccc}
\hline Sample & $R(\Omega)$ & $R(\Omega)$ & \multicolumn{2}{c}{$C$} & $C \times \frac{O}{R}\left(\mathrm{~mm}^{2} / \Omega\right)$ \\
\hline 1 & 5 & 210 & 0.83 & $\mathrm{E}-16$ & $4 \mathrm{E}-18$ \\
2 & 5 & 210 & 1.6 & $\mathrm{E}-16$ & $8 \mathrm{E}-18$ \\
3 & 10 & 33.3 & 3.5 & $\mathrm{E}-17$ & $7.9 \mathrm{E}-18$ \\
4 & 10 & 33.3 & 3.1 & $\mathrm{E}-17$ & $6.9 \mathrm{E}-18$ \\
5 & 10 & 420 & 3.3 & $\mathrm{E}-16$ & 8 \\
6 & 10 & 420 & 4.2 & $\mathrm{E}-16$ & $10.5 \mathrm{E}-18$ \\
7 & 45 & 150 & 7.3 & $\mathrm{E}-17$ & $3.6 \mathrm{E}-18$ \\
8 & 75 & 81 & 1.1 & $\mathrm{E}-16$ & $8.4 \mathrm{E}-18$ \\
\hline
\end{tabular}

From table $\mathrm{I}$ it is seen that the quantity $\mathrm{C} \times \mathrm{O} / \mathrm{R}$ is nearly constant. This means according to (4):

$<\frac{\Delta \mathrm{R}^{2}}{\mathrm{R}^{2}}>=$ constant $\times \frac{\mathrm{R}}{\mathrm{O}} \frac{\Delta \mathrm{f}}{\mathrm{f}}$

Besides the fact that relation (5) gives a low noise design criterion, combined with expression (3) one finds:

$<\frac{\Delta \mathrm{r}_{\mathrm{v}}^{2}}{\mathrm{r}_{\mathrm{v}}^{2}}>=$ constant $\times \mathrm{r}_{\mathrm{v}} \frac{\Delta \mathrm{f}}{\mathrm{f}}$

Relation (6) gives some more information about the grains noise. A relation similar to (5) was found for noise in thin metal films, ${ }^{4}$ where the noise is assumed to be caused by the modulation of the tunnelprobability. This is perhaps also an argument in favour of the tunnel mechanism in thick film resistors.

\section{CONCLUSIONS}

Thin and thick film resistors show excellent noise performance, so that if one is interested in measuring it, for instance in accordance with stability tests, it is a hard problem to solve. In this paper some reliable measurement arrangements are described.

As shown in section 3 , high quality films do not always show current noise in the normal investigated frequency range $618-1618 \mathrm{~Hz}$, which means that measurements have to be carried out at lower frequencies.

On the other hand it is shown that current noise is most likely a volume noise in the case of sufficiently thick films. For extremely thin films the answer is not straightforward. From measured data a dependence of the noise on resistor area and sheet resistance is obtained. This allowed us to gain some insight in the mechanism of current noise.

\section{REFERENCES}

1. S. Demolder, M. Vandendriessche and A. Van Calster, "The measuring of $1 / \mathrm{f}$ noise of thick and thin film resistors", J. Phys. E, 13 p 1323 (1980).

2. L.K.J. Vandamme, "Criteria of low-noise thick-film resistors", Electrocomponent Science and Technology, 4 p 171 (1977).

3. A. Cattanes, L. Pirozzi, B. Morten and M. Prudenziati, "Influence of the substrate on the electrical properties of thick-film resistors", ISHM Europe Gent Conference p 123 (1979).

4. P. Mazzetti and A. Stepanescu, "Mechanism of noise formation in electric conduction in thin metal films", Thin Solid Films, 13 p 67 (1972). 

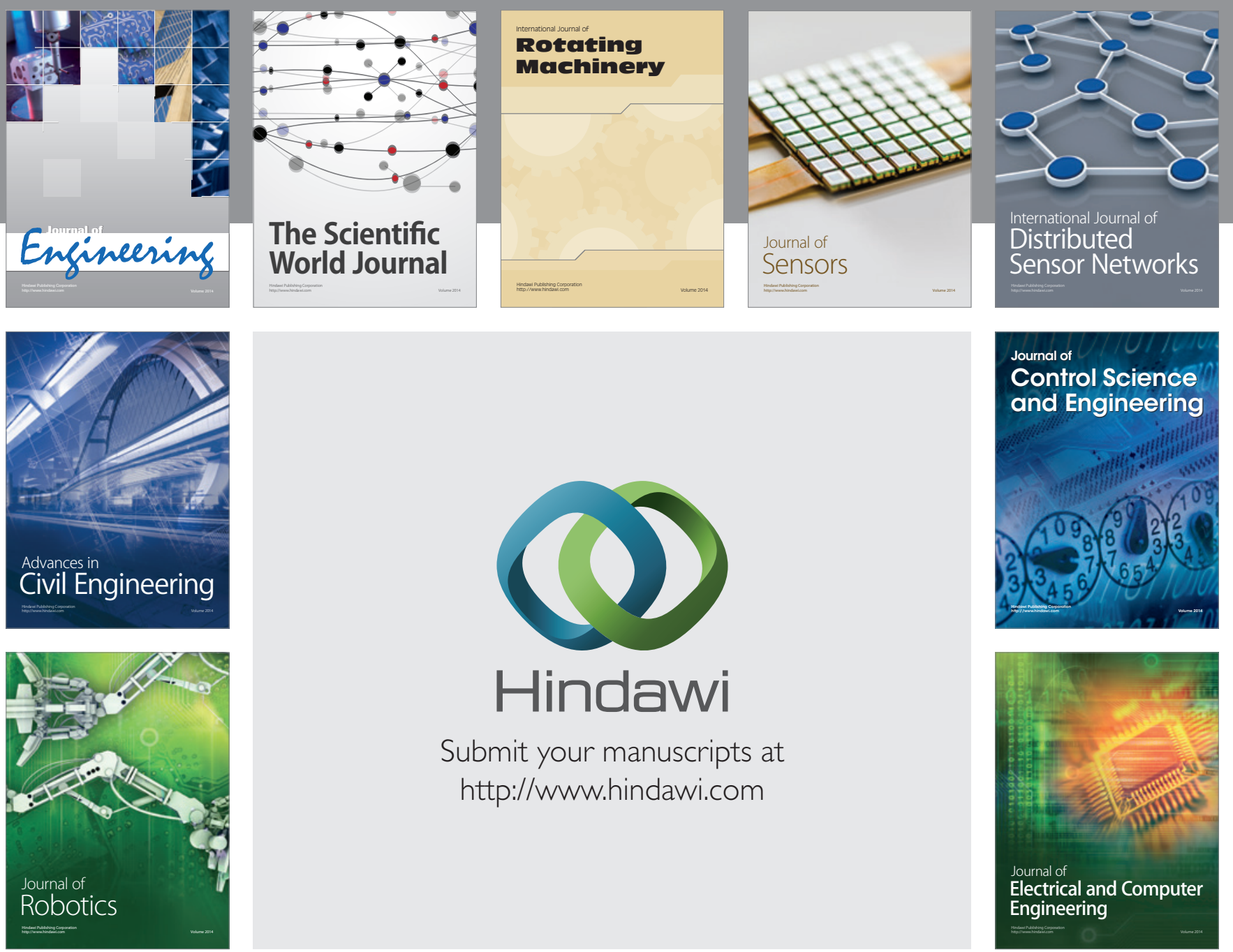

Submit your manuscripts at

http://www.hindawi.com
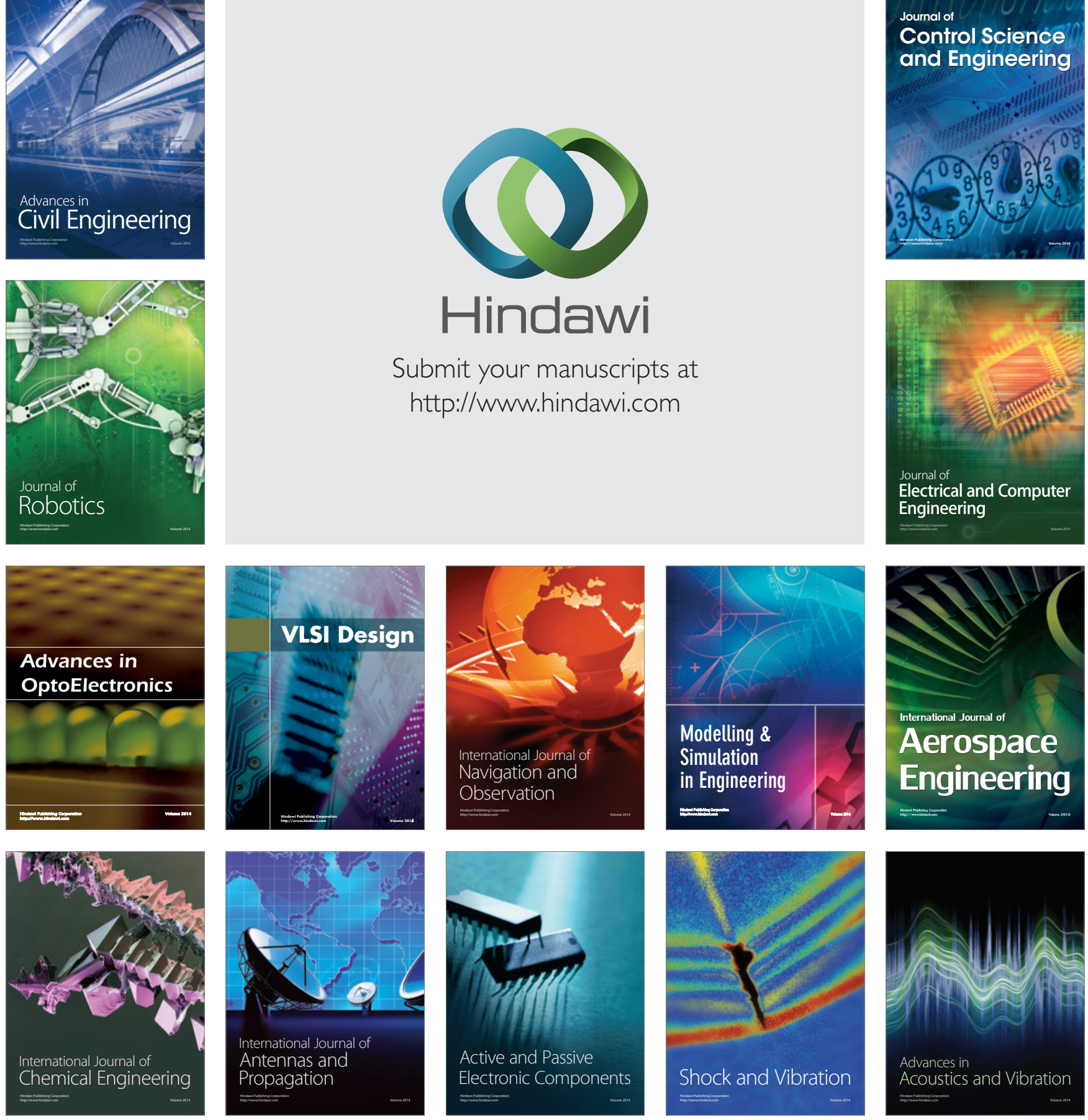